09,12

\title{
Температурное тушение и деполяризация флюоресценции углеродных наноточек полученных пиролизом парафина
}

\author{
() А.Н. Старухин, Д.К. Нельсон, Д.А. Курдюков, Д.А. Еуров, В.Г. Голубев \\ Физико-технический институт им. А.Ф. Иофрфе, \\ Санкт-Петербург, Россия \\ E-mail: a.starukhin@mail.ioffe.ru
}

(Поступила в Редакцию 2 июля 2018 г.)

Исследовано влияние температуры на интенсивность и поляризацию флюоресценции коллоидной системы углеродных наноточек в глицерине в условиях линейно поляризованной накачки. Наноточки получены путем пиролиза парафина в нанопорах мезопористого кремнезема. Показано, что повышение температуры приводит к тушению флюоресценции наноточек и оценена энергия активации процесса тушения. Установлено, что экспериментальная зависимость степени линейной поляризации флюоресценции от температуры описывается уравнением Левшина-Перрена, учитывающим вращательную диффузию люминесцирующих частиц (флюорофоров) в жидкой матрице. Размер флюорофоров в рамках модели Левшина-Перрена оказывается заметно меньше размеров углеродных наноточек. Отличие размеров флюорофора и наноточки указывает, что малые атомные группы, ответственные за люминесценцию наноточки, характеризуются высокой сегментарной подвижностью.

Работа выполнена при частичной поддержке РФФИ (проект № 16-03-00472).

DOI: 10.21883/FTT.2018.12.47353.186

\section{1. Введение}

Углеродные наноточки являются одним из новых видов наноматериалов, обладающих уникальным набором физико-химических свойств. Основу наноточки составляет ядро, представляющее собой нанокластер атомов углерода в состоянии $s p^{2}$-гибридизации, характерной для графита [1]. С поверхностью ядра связаны различные атомные группы (карбонильные, карбоксильные и другие), которые в существенной степени определяют оптические свойства, химическую активность, степень гидрофильности и другие характеристики углеродных наноточек [2-5]. Возможность функционализации поверхности наноточек различными атомными группами открывает возможность целенаправленного изменения их свойств [6,7]. Углеродные наноточки отличаются простотой синтеза, дешевизной, малой токсичностью и химической инертностью, что выгодно отличает их от полупроводниковых квантовых точек. Наряду с применением в оптоэлектронике, устройствах хранения и преобразования энергии, катализе, углеродные наноточки вызывают особый интерес с точки зрения различных биомедицинских приложений [8-10].

В основе многих приложений углеродных наноточек лежат их люминесцентные свойства. В связи с этим фундаментальной задачей исследования фотофизических свойств углеродных наноточек является установление природы оптических переходов в этих объектах, которая остается неясной [8]. Спектры оптического поглощения и люминесценции углеродных наноточек представляют собой широкие полосы. Это не позволяет применить для изучения свойств электронных состояний в данных системах высокоинформативные методы спектроскопии высокого разрешения. Эффективным методом изучения свойств излучательных состояний, формирующих широкополосные спектры, является изучение влияния внешних факторов (температуры, поляризации и интенсивности оптического возбуждения) на их люминесцентные свойства. В частности, метод поляризованной люминесценции [11-13] позволяет получать информацию о структуре элементарных излучателей, их взаимодействии между собой и с окружающей средой даже в случае широкополосных спектров. Целью настоящей работы явилось исследование влияния температуры на интенсивность и степень поляризации люминесценции углеродных наноточек, полученных методом пиролиза парафина в нанопорах мезопористого кремнезема. Установлено, что повышение температуры приводит к гашению люминесценции и ее деполяризации (в условиях линейно поляризованного возбуждения). Показано, что деполяризация излучения описывается уравнением Левшина-Перрена, связывающего деполяризацию излучения люминофора с его вращением. В рамках модели Левшина-Перрена оценен размер излучающих частиц, который указывает на сегментарную подвижность фрагментов наноточек, ответственных за их флюоресценцию.

\section{2. Эксперимент}

Существует значительное разнообразие методов синтеза углеродных наноточек. Углеродные наноточки, исследованные в настоящей работе, были получены путем термического разложения парафина в порах мезопористого кремнезема. Диаметр пор составлял $~ 3 \mathrm{~nm}$ [14]. 
Метод синтеза углеродных наноточек в мезопористом кремнеземе ранее успешно применялся для получения углеродных наноточек из других прекурсоров $[14,15]$. Частицы мезопористого кремнезема пропитывались жидким парафином, после чего отжигались на воздухе при температуре $400^{\circ} \mathrm{C}$. Синтезированные наноточки экстрагировались из твердотельной матрицы глицерином. Исследовались коллоидные растворы наноточек в глицерине. В отличие от бесцветного глицерина растворы углеродных наноточек окрашены в светлокоричневый цвет.

Люминесценция углеродных наноточек возбуждалась линейно поляризованным лазерным излучением с длиной волны $\lambda_{\text {exc }}=405 \mathrm{~nm}$. Плотность возбуждения составляла $\sim 0.2 \mathrm{~W} / \mathrm{cm}^{2}$. Регистрация оптических спектров проводилась с использованием дифракционного спектрометра. Степень поляризации люминесценции измерялась с помощью кварцевого модулятора [16] и линейного поляризатора в сочетании с двухканальной системой счета фотонов. Измерения проводились в „90-геометрии“ (направления распространения возбуждающего и излучаемого света взаимно перпендикулярны).

\section{3. Результаты и обсуждение}

\section{1. Температурное тушение флюоресценции}

Спектр флюоресценции исследованных наноточек в условиях непрерывного возбуждения светом с $\lambda_{\text {exc }}=405 \mathrm{~nm}$ при $T=298 \mathrm{~K}$ представлен на рис. 1 . Спектр представляет собой широкую ассиметричную полосу с максимумом при $\lambda_{\max }=490 \mathrm{~nm}$, занимающую весь видимый спектр. С увеличением температуры раствора интенсивность флюоресценции наноточек падает (рис. 1), при этом форма спектра претерпевает изменения. Эти изменения иллюстрирует рис. 2, на

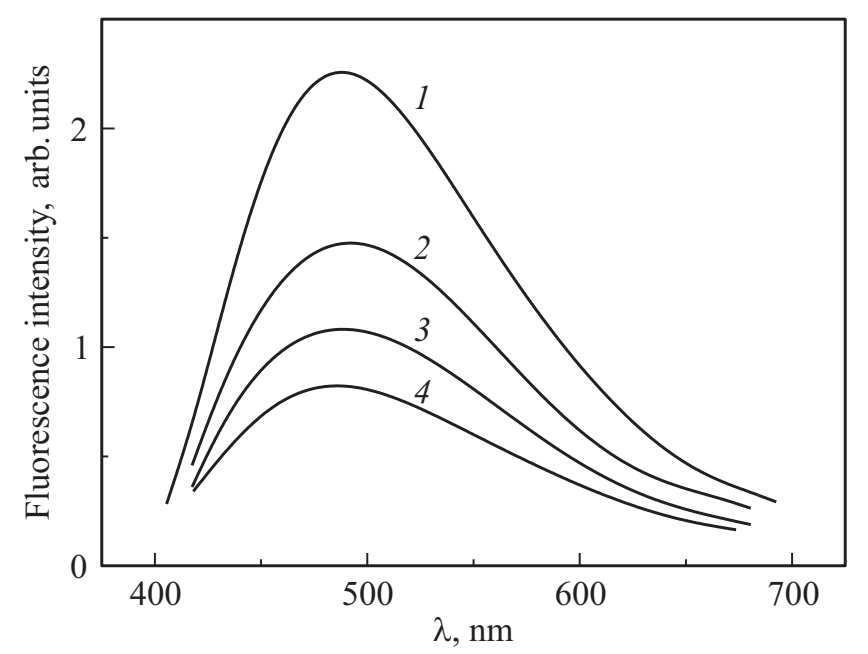

Рис. 1. Спектры флюоресценции углеродных наноточек в глицерине при температурах $298 \mathrm{~K}$ (1), $333 \mathrm{~K}$ (2), $373 \mathrm{~K}$ (3) и $430 \mathrm{~K}(4) . \lambda_{\text {exc }}=405 \mathrm{~nm}$.

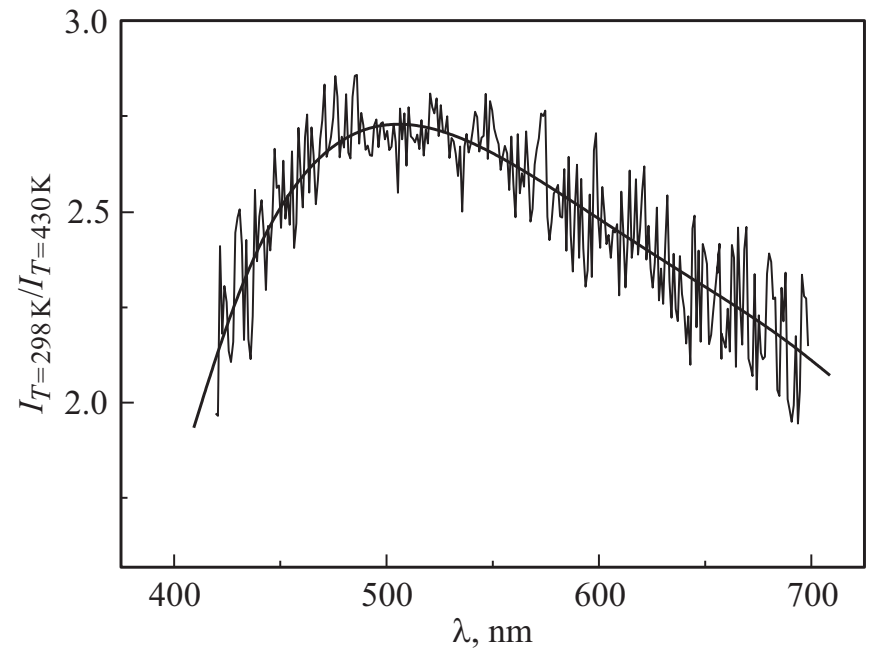

Рис. 2. Экспериментальная зависимость отношения интенсивностей флюоресценции при температурах $298 \mathrm{~K}$ и $430 \mathrm{~K}$, $I_{T=298 \mathrm{~K}} / I_{T=430 \mathrm{~K}}$ от длины волны излучения. $\lambda_{e x c}=405 \mathrm{~nm}$.

котором приведена зависимость отношения интенсивностей флюоресценции при температурах $298 \mathrm{~K}$ и $430 \mathrm{~K}$, $I_{T=298 \mathrm{~K}} / I_{T=430 \mathrm{~K}}$, от длины волны излучения. Как следует из рисунка, эффект температурного тушения флюоресценции максимален для излучательных состояний в области максимума полосы излучения и уменьшается по мере удаления от максимума, то есть для излучателей с $\lambda<\lambda_{\max }$ и $\lambda>\lambda_{\max }$. На рис. 3 в полулогарифмическом масштабе приведены экспериментальные зависимости интенсивностей флюоресценции углеродных наноточек от обратной температуры, $I(1 / T)$, для двух произвольно выбранных длин волн в области максимума полосы излучения $(\lambda=490 \mathrm{~nm})$ и на ее длинноволновом крыле $(\lambda=580 \mathrm{~nm})$.

При малой интенсивности возбуждения интенсивность флюоресценции $I$ определяется интенсивностью накачки $I_{\text {exc }}$ и соотношением излучательного $\tau_{r}$ и безызлучательного $\tau_{0}$ времен жизни возбужденного излучательного состояния [17]

$$
I \propto \frac{\tau_{0}}{\tau_{r}+\tau_{0}} I_{e x c}=\frac{\tau}{\tau_{r}} I_{e x c}
$$

Здесь $\tau=\left(\tau_{r}^{-1}+\tau_{0}^{-1}\right)^{-1}-$ полное время жизни излучательного состояния. Согласно (1) тушение флуоресценции при увеличении температуры связано с уменьшением безызлучательного времени жизни возбужденного состояния. Уменьшение безызлучательного времени жизни с повышением температуры может быть объяснено усилением столкновительных процессов в молекулярной системе, что способствует дезактивации возбужденных электронных состояний путем безызлучательной колебательной релаксации молекул. В рамках такого подхода [17] зависимость безызлучательного времени жизни возбужденного состояния от температуры 


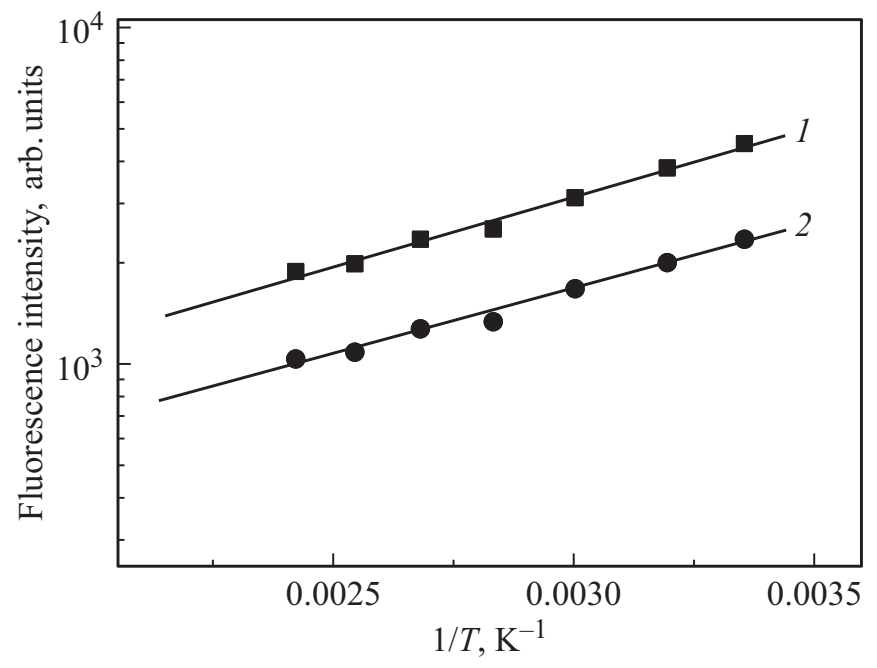

Рис. 3. Зависимости интенсивностей флюоресценции углеродных наноточек от температуры для различных спектральных участков полосы излучения с $\lambda=490 \mathrm{~nm}$ (1) и с $\lambda=580 \mathrm{~nm} \mathrm{(2).} \mathrm{Точки} \mathrm{-} \mathrm{экспериментальные} \mathrm{значения,}$ сплошные линии - аппроксимации экспериментальных зависимостей уравнением (4).

определяется выражением

$$
\tau_{0}^{-1}(T)=B \exp \left(-\frac{E_{A}}{k T}\right),
$$

где $E_{A}$ - энергия активации процесса безызлучательного распада возбужденного состояния, $B-$ постоянная, имеющая смысл вероятности безызлучательного распада при $T \rightarrow \infty$. С учетом (2) соотношение (1) может быть записано в виде

$$
I(T)=\frac{I(0)}{1+C \exp \left(-\frac{E_{A}}{k T}\right)},
$$

где $C \equiv \tau_{r} B$. При высоких температурах, таких что $C \exp \left(-E_{A} / k T\right) \gg 1$, зависимость интенсивности от обратной температуры носит экспоненциальный характер

$$
I(T)=[I(0) / C] \exp \left(E_{A} / k T\right) .
$$

На рис. 3 представлены результаты аппроксимации экспериментальных зависимостей $I(1 / T)$ для длин волн излучения 490 и $580 \mathrm{~nm}$ соотношением (4). В полулогарифмическом масштабе зависимости $I(1 / T)$, описываемые (4), имеют вид отрезков прямых (рис. 3), наклон которых к оси абсцисс определяет энергии активации $E_{A}$. Энергии активации, которые характеризуют процессы безызлучательного распада состояний, ответственных за излучение с длинами волн 490 и $580 \mathrm{~nm}$, оказались несколько различными, 87 и $80 \mathrm{meV}$ соответственно. Это различие согласуется с данными рис. 2, согласно которым состояния, формирующие максимум полосы флюоресценции, более чувствительны к температуре, чем состояния, отвечающие длинноволновому крылу полосы. Приведенные выше значения энергий активации для наноточек на основе парафина оказываются заметно больше, чем для наноточек, синтезированных из иных прекурсоров (смеси ледяной уксусной кислоты и пятиокиси фосфора) [18].

\section{2. Поляризованная флюоресценция}

Исследования флюоресценции показали, что при возбуждении линейно поляризованным светом излучение углеродных наноточек преимущественно линейно поляризовано в той же плоскости, что и возбуждающий свет. Степень линейной поляризации максимальна на коротковолновом краю полосы излучения и уменьшается по мере увеличения длины волны. При возбуждении наноточек циркулярно поляризованным светом их излучение остается неполяризованным.

Известно, что в отсутствие внешних полей коллоидная система с жидкой средой оптически изотропна [19]. Наблюдаемая фотоиндуцированная линейная поляризация излучения указывает на скрытую оптическую анизотропию системы. Особенности поляризованной люминесценции наноточек могут быть объяснены в рамках осцилляторной модели [11]. В рамках этой модели ансамбль фотовозбужденных наноточек следует рассматривать как систему линейных полностью анизотропных дипольных осцилляторов, ориентация которых в пространстве носит случайный характер. Линейно поляризованный свет возбуждает преимущественно осцилляторы, дипольные моменты которых ориентированы параллельно вектору Е световой волны. Если за время жизни излучательного состояния (время затухания осциллятора) ориентации дипольных моментов существенно не изменятся, излучение системы осцилляторов будет преимушественно поляризовано в той же плоскости, что и возбуждающий свет.

\section{3. Температурная зависимость поляризации излучения}

Возбуждающий свет, поляризованный с $E \| z$, распространялся вдоль оси $y,\left(k_{e x c} \| y\right)$, излучение образца регистрировалось в направлении оси $x\left(k_{\text {emis }} \| x\right)$. Измерялись интенсивность $I$ и степень линейной поляризации излучения $P$

$$
P=\frac{I_{z}-I_{y}}{I_{z}+I_{y}}
$$

где $I_{z}$ и $I_{y}-$ интенсивности компонент излучения, поляризованных с $E \| z$ и $E \| y$ соответственно ${ }^{1}$.

При фиксированной температуре степень поляризации излучения зависит от длины волны $P=P(\lambda)$. В случае углеродных наноточек, полученных пиролизом парафина, эта зависимость оказывается близкой

\footnotetext{
1 Заметим, что при линейно поляризованной накачке с $E \| z$ полная интенсивность излучения $I=I_{z}+2 I_{y}[13]-$ именно эта интенсивность анализировалась выше при рассмотрении эффекта температурного тушения флюоресценции.
} 


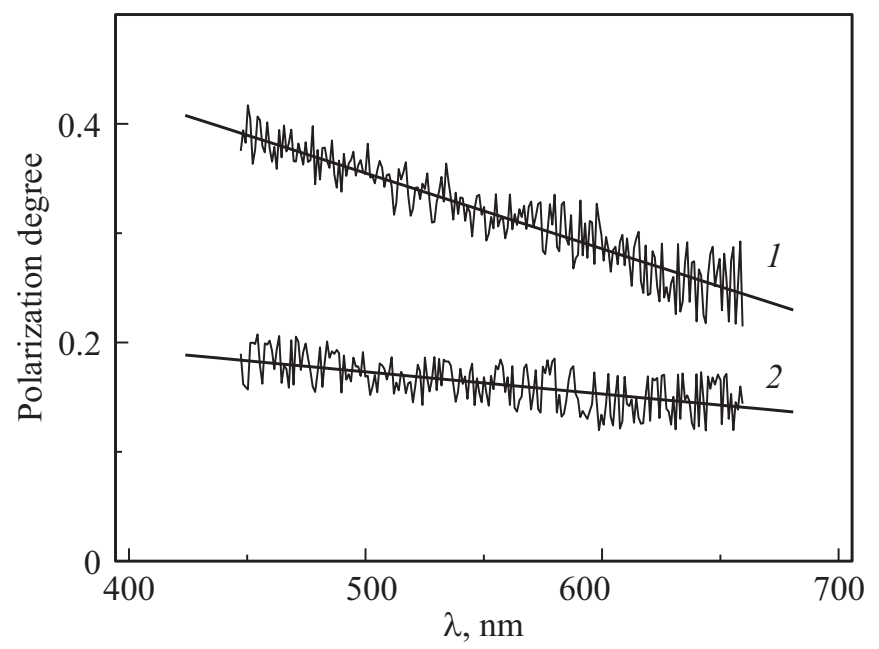

Pис. 4. Экспериментальные зависимости степени линейной поляризации излучения углеродных наноточек от длины волны излучения при температурах: $298 \mathrm{~K}$ (1) и $353 \mathrm{~K}(2)$.

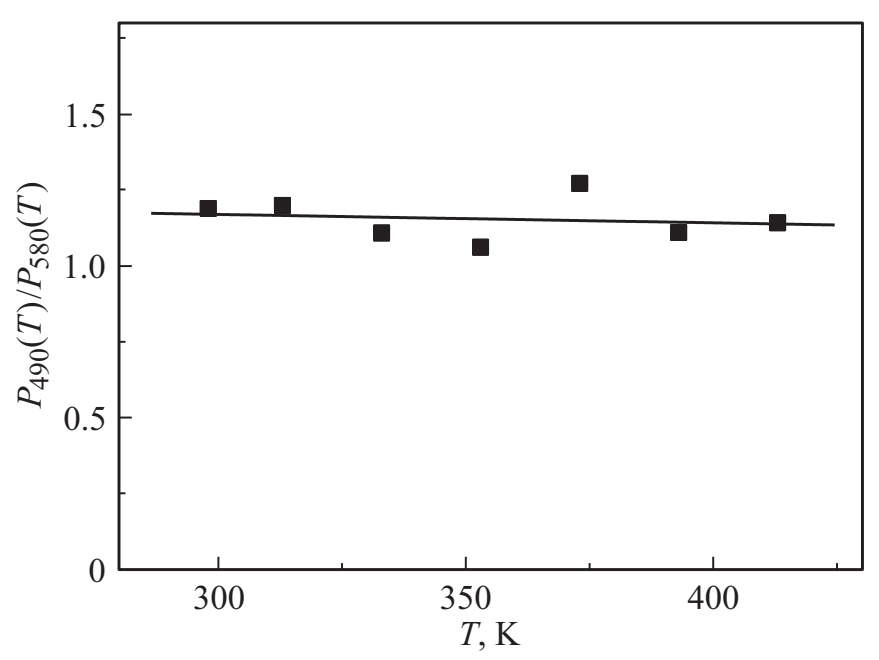

Рис. 5. Экспериментальная зависимость отношения степени поляризации излучения в максимуме полосы излучения $(\lambda=490 \mathrm{~nm})$ и на ее длинноволновом крыле $(\lambda=580 \mathrm{~nm})$, $P_{490}(T) / P_{580}(T)$ от температуры.

к линейной (рис. 4). Повышение температуры приводит к деполяризации излучения, при этом относительное уменьшение степени поляризации оказывается практически одинаковым для различных длин волн. На рис. 5 представлена зависимость от температуры отношения степени поляризации излучения в максимуме полосы излучения $(\lambda=490 \mathrm{~nm})$ и на ее длинноволновом крыле $(\lambda=580 \mathrm{~nm}), P_{490}(T) / P_{580}(T)$. Как видно из рисунка это отношение практически постоянно $P_{490}(T) / P_{580}(T)=1.15 \pm 0.05 \approx$ const.

В разбавленных растворах можно пренебречь миграцией энергии между различными наноточками. В этом случае, как показывает опыт молекулярной спектроскопии $[11,13]$, определяющим механизмом деполяризации излучения коллоидных растворов может быть броуновское вращение частиц (и соответственно связанных с ними дипольных осцилляторов). Тепловое движение молекул раствора нарушает первоначальное (созданное светом) анизотропное распределение осцилляторов по направлениям их дипольных моментов, стремясь к изотропизации функции распределения. Степень деполяризации определяется углом поворота молекулы за время жизни возбужденного состояния, который зависит от ее размера, температуры и вязкости среды. Зависимость степени линейной поляризации излучения сферических молекул от температуры раствора описывается уравнением Левшина-Перрена [11-13]

$$
\begin{aligned}
\frac{1}{P(T)} & =\frac{1}{P_{0}}+\left(\frac{1}{P_{0}}-\frac{1}{3}\right) \frac{k T \tau(T)}{\eta(T) V} \\
& =\frac{1}{P_{0}}+\frac{1}{V}\left(\frac{1}{P_{0}}-\frac{1}{3}\right) x,
\end{aligned}
$$

где $k$ - постоянная Больцмана, $T-$ температура раствора, $\tau(T)$ - время жизни излучательного состояния, $\eta(T)$ - динамическая вязкость растворителя, $V$ - объем молекулы, $x \equiv k T \tau / \eta, P_{0}-$ предельное значение степени поляризации (при $\eta \rightarrow \infty)$. При случайной ориентации дипольных моментов элементарных излучателей максимальное значение $P_{0}=0.5$ достигается при одинаковой ориентации фотовозбужденного (поглощающего) и излучающего свет диполей. В соответствии с (6) увеличение температуры уменьшает степень поляризации излучения вследствие усиления броуновского движения и уменьшения вязкости среды. С другой стороны, это увеличение повышает скорость безызлучательного распада излучательного состояния и приводит к уменьшению $\tau$, что способствует увеличению $P$.

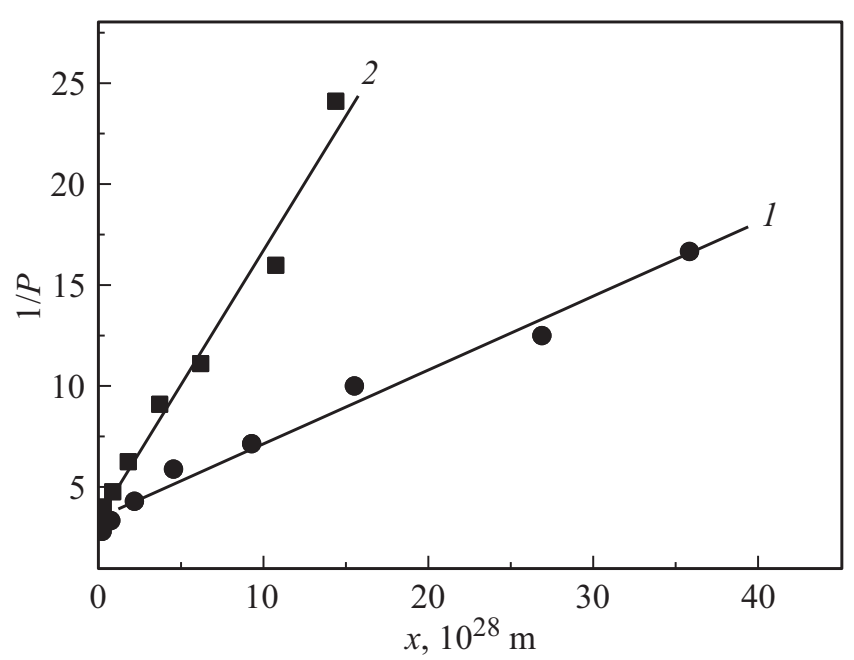

Рис. 6. Зависимости $P^{-1}(x)$ для различных спектральных участков полосы излучения с $\lambda=490 \mathrm{~nm}$ (1) и с $\lambda=580 \mathrm{~nm}(2)$. Точки - экспериментальные значения, сплошные линии - аппроксимации экспериментальных зависимостей уравнением (6). 
Экспериментальные зависимости $P^{-1}(x)$ для различных спектральных участков полосы излучения представлены на рис. 6. Значения переменной $x$ вычислялись с учетом температурной зависимости $\eta(T)[20]$ и $\tau(T)$. Зависимость $\tau(T)$ определялась на основе температурной зависимости интенсивности флюоресценции $I(T)$, которая при малых интенсивностях возбуждения (область линейной зависимости $I$ от $\left.I_{\text {exc }}\right)$ пропорциональна $\tau(T)$ : [см. (1)]. Если $I_{\text {exc }}=$ const, $I(T) \propto \tau(T)$. При анализе экспериментальных данных учитывалось, что при фиксированной температуре время жизни флюоресцентного состояния $\tau$ меняется с длиной волны излучения $[21,22]$. При вычислении переменной $x$ принималось, что при комнатной температуре в максимуме полосы флюоресценции $\tau \sim 5 \mathrm{~ns}$ [21-23]. Как видно из рис. 6 экспериментальные зависимости $P^{-1}(x)$ удовлетворительно описываются уравнением (6), что указывает на „вращательный механизм“ деполяризации излучения наноточек.

Сравнение эксперимента с теорией дало возможность оценить объем люминесцирующих частиц. С точностью $10 \%$ линейные размеры люминофоров, отвечающих за излучение различных длин волн, оказались практически одинаковы $\sim 0.9 \mathrm{~nm}$. Интересно сравнить размеры люминофора и наноточки. Можно предположить, что размеры углеродных наноточек, синтезированных в нанопорах мезопористого кремнезема в значительной степени определяются размерами нанопор. В частности, установлено, что углеродные наноточки, синтезируемые в мезопористом кремнеземе из аминопропилтриэтоксисилана (APTES), имеют размеры $(\sim 3.3 \mathrm{~nm})$, практически совпадающие с диаметром нанопор $(\sim 3 \mathrm{~nm})$ [14]. Можно полагать, что аналогичное соотношение размеров нанопор и наноточек сохраняется и в случае, когда прекурсором для получения углеродных наноточек является парафин. В этом случае размеры люминофоров, ответственных за флюоресценцию углеродных наноточек, оказываются заметно меньше размера наноточек. Как отмечалось выше, с поверхностью графитового ядра наноточек связаны различные атомные группы, которые в существенной степени определяют оптические свойства наноточек. Описанное несоответствие размеров излучателя (собственно люминофора) и наноточки можно объяснить тем, что атомные группы, ответственные за люминесценцию наноточек, слабо связаны с их ядром и могут вращаться почти независимо от него. Аналогичное соотношение между размерами люминофоров, ответственных за флюоресценцию углеродных наноточек, и размерами наноточек следует также из ряда других экспериментов по поляризованной флюоресценции углеродных наноточек [22,24], в частности, из анализа времени затухания анизотропии флюоресценции углеродных наноточек при комнатной температуре. Таким образом, указанное соотношение является достаточно общим свойством углеродных наноточек, полученных по разной технологии и из разных прекурсоров. Заметим, что сегментарная подвижность отдельных фрагментов молекулярных комплексов наблюдается и в других молекулярных системах, например, в комплексах, состоящих из малой молекулы красителя и молекулы ДНК [25].

\section{4. Заключение}

Таким образом, в работе изучено влияние температуры на интенсивность и поляризационные характеристики флуоресценции углеродных наноточек, синтезированных в нанопорах мезопористого кремнезема путем термического разложения парафина. Установлено, что повышение температуры ведет к тушению флюоресценции и ее деполяризации (в условиях линейно поляризованной накачки). Определена энергия активации процесса тушения флюоресценции, которая заметно отличается от энергий активации для углеродных наноточек, синтезированных из других прекурсоров. Показано, что деполяризация излучения при повышении температуры описывается уравнением Левшина-Перрена, что указывает на вращательный механизм деполяризации. Из сравнения экспериментальной и теоретической зависимостей оценены размеры вращающихся излучателей. Результаты свидетельствуют, что атомные группы в наноточках, ответственные за фотолюминесценцию, обладают значительной локальной подвижностью.

\section{Список литературы}

[1] M. Sharon, M. Sharon. Graphene: An Introduction to the Fundamentals and Industrial Applications. John Wiley \& Sons, Hoboken (2015). 294 p.

[2] Y.-P. Sun, B. Zhou, Y. Lin, W. Wang, K.A.S. Fernando, P. Pathak, M.J. Meziani, B.A. Harruff, X. Wang, H. Wang, P.G. Luo, H. Yang, M.E. Kose, B. Chen, L.M. Veca, S.-Y. Xie. J. Am. Chem. Soc. 128, 7756 (2006).

[3] A.B. Bourlinos, A. Stassinopoulos, D. Anglos, R. Zboril, V. Georgakilas, E.P. Gia. Chem. Mater. 20, 4539 (2008).

[4] Y. Wang, A. Hu. J. Mater. Chem. C 2, 6921 (2014).

[5] M.A. Jhonsi, S. Thulasi. Chem. Phys. Lett. 661, 179 (2016).

[6] X. Wang, L. Cao, S.-T. Yang, F. Lu, M.J. Meziani, L. Tian, K.W. Sun, M.A. Bloodgood, Y.-P. Sun. Angew. Chem. Int. Ed. 49, 5310 (2010).

[7] H. Peng, J. Travas-Sejdic. Chem. Mater. 21, 5563 (2009).

[8] R. Jelinek. Carbon Quantum Dots. Springer International Publishing, Switzerland (2017) 133 p.

[9] S.-T. Yang, X. Wang, H. Wang, F. Lu, P.G. Luo, L. Cao, M.J. Meziani, J.-H. Liu, Y. Liu, M. Chen, Y. Huang, Y.-P. Sun. J. Phys. Chem. C 113, 18110 (2009).

[10] F. Yuan, S. Li, Z. Fan, X. Meng, L. Fan, S. Yang. Nano Today 11, 565 (2016).

[11] П.П. Феофилов. Поляризованная люминесценция атомов, молекул и кристаллов. Физматгиз, М. (1959). 288 с. [P.P. Feofilov. The Physical Basic of Polarized Emission. Consultants Bureau, N. Y. (1961). 274 p.].

[12] D.S. Kliger, J.W. Lewis, C.E. Randall. Polarized Light in Optics and Spectroscopy, Academic Press Inc., San Diego (1990). $304 \mathrm{p}$.

[13] J.R. Lakowicz. Principles of Fluorescence Spectroscopy. Springer Science + Business Media (2006). 954 p.

[14] Д.А. Курдюков, Д.А. Еуров, Е.Ю. Стовпяга, Д.А. Кириленко, С.В. Коняхин, А.В. Швидченко, В.Г. Голубев. ФТТ 58, 2454 (2016).

[15] J. Zong, Y. Zhu, X. Yang, J. Shen, C. Li. Chem. Commun. 47, 764 (2011). 
[16] S.N. Jasperson, S.E. Schnatterly. Rev. Sci. Instr. 40, 761 (1969).

[17] J.I. Pankove. Optical processes in semiconductors. Dover Publications Inc., N. Y. (2010). 448 p.

[18] P. Yu, X. Wen, Y.-R. Toh, J. Tang. J. Phys. Chem. C 116, 25552 (2012).

[19] Д.А. Фридрихсберг. Курс коллоидной химии, Химия, Л. (1984). 568 c.

[20] Physical Properties of Glycerine and Its Solutions. Glycerine Producers' Association, N. Y. (1963).

[21] A. Sharma, T. Gadly, A. Gupta, A. Ballal, S.K. Ghosh, M. Kumbhakar. J. Phys. Chem. Lett. 7, 3695 (2016).

[22] M.O. Dekaliuk, O. Viagin, Y.V. Malyukin, A.P. Demchenko. Phys. Chem. Chem. Phys. 16, 16075 (2014).

[23] D.K. Nelson, B.S. Razbirin, A.N. Starukhin, D.A. Eurov, D.A. Kurdyukov, E.Yu. Stovpiaga, V.G. Golubev. Opt. Mater. 59, 28 (2016).

[24] А.Н. Старухин, Д.К. Нельсон, Д.А. Курдюков, Д.А. Еуров, Е.Ю.Стовпяга, В.Г. Голубев. Письма в ЖЭТФ 107, 227 (2018).

[25] J.R. Unruh, G. Gokulrangan, G.H. Lushington, C.K. Johnson, G.S. Wilson. Biophys. J. 88, 3455 (2005).

Редактор К.В. Емцев 